\title{
Rubber Processing Effluent Treatment with Chitosan: A Natural Biopolymer in Comparison with a Synthetic Coagulant
}

\author{
Christie O. Ize-lyamu ${ }^{1}$, Hilary I. Ifijen ${ }^{1^{*}}$, Osaro K. Ize-Iyamu², \\ Justina E. Ukpebor ${ }^{3}$ and Emmanuel E. Ukpebor ${ }^{3}$ \\ ${ }^{1}$ Department of Research Operations, Rubber Research Institute of Nigeria (RRIN), Km. 19, \\ Benin-Sapele Road, Iyanomo, Edo State, Nigeria \\ ${ }^{2}$ Department of Chemistry, Faculty of Natural Sciences, Ambrose Alli University, Ekpoma, \\ Edo State, Nigeria \\ ${ }^{3}$ Department of Chemistry, Faculty of Physical Sciences, University of Benin, Benin-city, \\ Edo State, Nigeria \\ *larylans4u@yahoo.com
}

Keywords: BOD, coagulation, COD, chitosan, deacetylation, effluent, flocculation, rubber

\begin{abstract}
Chitosan, a naturally occurring biopolymer extracted from prawn heads was used in the treatment of crump rubber processing effluent for safe disposal into the environment. The triplicate analyses of the effluent samples obtained by composite sampling method indicated high levels of pollution which violated the permissible limits of environmental discharge standards with a low dissolved oxygen (DO) $0.63 \mathrm{mg} / \mathrm{L}$, biochemical oxygen demand (BOD) $312.00 \pm 1.32 \mathrm{mg} / \mathrm{L}$ and chemical oxygen demand (COD) $1069.58 \pm 2.42 \mathrm{mg} / \mathrm{L}($ mean $\pm \mathrm{SD})$ levels respectively. Chitosan was analyzed according to standard procedures; it showed good coagulative potentials from the elemental analysis and a degree of deacetylation of $76.5 \%$. The crump rubber processing effluent was treated with chitosan and Iron (III) Chloride respectively by coagulation and flocculation methods and the results obtained via the physicochemical characterization of the treated effluent showed that the use of chitosan as a coagulant compared favourably with Iron (III) Chloride after treatment. DO levels increased from $0.63 \mathrm{mg} / \mathrm{L}$ to $3.90 \mathrm{mg} / \mathrm{L}$. There were also a remarkable reduction in the Turbidity, BOD and COD levels of the treated samples by over $80 \%$ respectively and $70 \%$ reduction in the nutrient levels. The efficacy of chitosan in comparison with Iron (III) Chloride suggests that it can be used as a replacement for synthetic coagulants based on its availability and environmental friendliness.
\end{abstract}

\section{Introduction}

Biopolymers are substances naturally produced by living organisms; in other words, they are polymeric [1]. They are considered to be eco-friendly and sustainable. This group consists of naturally occurring polymers; cellulose, starch, lignin, chitin, and various polysaccharides. These materials and their derivatives offer a wide range of properties and applications.

Chitosan the natural cationic biopolymer derived from chitin has received growing attention because it's biodegradable, biocompatible, non-toxic and has the ability to target specific delivery properties [2]. It is a linear polysaccharide composed of randomly distributed $\beta(1-4)$ linked Dglucosamine (deacetylated unit) and $\mathrm{N}$-acetyl D-glucosamine (acetylated unit). Chitosan is composed of $\mathrm{NH}_{2}$ (amino) group attached to a polyglucosamine chain. It is widely used in a range of diverse fields, including waste management.

Chitosan is very significant owing to its availability, ease of modification, application potential. It's coagulating and flocculating effects have helped in wastewater clarification, while minimizing the dependability on synthetic polyelectrolytes [3]. There are also man-made coagulants that are used for coagulation purposes. Inorganic coagulants which are also known as electrolytes have been known to be effective in water clarification and sludge conditioning [4]. Examples include; Aluminum sulphate, iron (III) chloride, iron (III) sulphate, iron (II) chloride, slaked lime, quick lime etc [4]. These chemicals ionize to their respective cations and anions that have respective 
coagulating abilities [5]. By the Schulze-Hardy rule, it is known that the coagulating ability of ions can be related to their valence [5]. The higher the electro-positive nature of the metal ion, the better is the coagulating property. In other words, the higher their valency, the better the coagulating properties of ions. For example, $\mathrm{Fe}^{3+}$ has better coagulating power than $\mathrm{Fe}^{2+}$ because it has a higher valency, A previous study established that the concentrations of $\mathrm{Na}^{+}, \mathrm{Ca}^{2+}$ and $\mathrm{Al}^{3+}$ required to coagulate and precipitate a negatively charged colloid are in the ratio 1000:10:1 respectively [5] . The effectiveness of aluminium and iron coagulants arises principally from their ability to form multi-charged polynuclear complexes with enhanced adsorption characteristics [6]. The nature of the complexes formed may be controlled by the $\mathrm{pH}$ of the system [6]. Natural polymers have long been used as coagulants and flocculants and they function by means of adsorption mechanism followed by charge neutralization or polymeric bridging effect [7]. The advantages of natural polymers are that they are biodegradable and are often locally available.

Chitosan is a biopolymer that has a highly linear structure and is insoluble in water, but it's soluble in dilute solutions of many organic and inorganic acids $(\mathrm{pH}<6)$, due to the protonation of the amino groups [8]. Other relevant properties of this biopolymer are its high molecular weight and porous structure which favors high water absorption $[9,10]$.

Chitosan extracted from the chitin of crustaceans has a structural function [11]. The process of deacetylation of chitin to obtain chitosan is a non-enzymatic process whereby chitosan is obtained by removing $\mathrm{N}$-acetylglucosamine unit $\left(\mathrm{R}-\mathrm{NHCOCH}_{3}\right)$ residue from chitin by treating it with strong alkali at high temperatures. When the degree of deacetylation is greater than $50 \%$, the biopolymer becomes soluble in acidic aqueous solutions and behaves as a cationic polyelectrolyte due to the protonation of amine groups in the presence of $\mathrm{H}^{+}$ions $[12,13]$. The positive charge of chitosan interacts strongly with the negative charges typical in most natural waters, wastewaters and sludge [14].

In this study, the effectiveness of chitosan as a coagulant in the treatment of Rubber Processing Effluent (RPE) for safe disposal was investigated and the data obtained were compared with the same effluent samples treated with Iron (III) Chloride.

\section{Materials and Methods}

\section{Materials}

Rubber processing effluent composite samples, Chitosan extracted from dried prawns, Sodium hydroxide, Hydrochloric acid, Acetic acid and all other chemicals used for physicochemical analysis of the untreated and treated effluent samples were of analytical grade and obtained from Sigma Aldrich Inc (USA). Type 1, Ultra pure deionized water was used for preparing all solutions.

\section{Chitosan extraction}

The dried prawn waste was ground into a fine powder with an electric blender, weighed and kept in a polyethylene bags at ambient temperature $\left(28 \pm 2^{\circ} \mathrm{C}\right)$ for 24 hours for partial autolysis to facilitate chemical extraction of chitosan $[15,16]$.

The following 3 (three) steps, namely Demineralization, Deproteinization and Deacetylation were followed for the conversion of chitin to chitosan [16].

\section{Degree of deacetylation determination}

Chitosan degree of deacetylation (DDA) was determined using an acid-base titration method [15]. In a typical determination, chitosan $(0.1 \mathrm{~g})$ was dissolved in $30 \mathrm{~mL} \mathrm{HCl}$ aqueous solution $(0.1 \mathrm{M})$ at room temperature with 5- 6 drops of methyl orange added. The red chitosan solution was titrated with $0.1 \mathrm{M} \mathrm{NaOH}$ solution until it turned orange. The DDA was calculated by the formula:

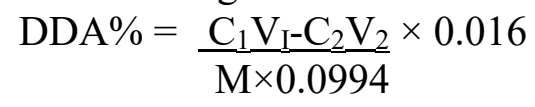

where, $\mathrm{C}_{1}=$ Concentration of standard $\mathrm{HCl}$ aqueous solution $(\mathrm{mol} / \mathrm{L})$,

$\mathrm{C}_{2}=$ Standard $\mathrm{NaOH}$ solution $(\mathrm{mol} / \mathrm{L})$, 
$\mathrm{V}_{1}=$ Volume of the standard $\mathrm{HCl}$ aqueous solution used to dissolve chitosan $(\mathrm{mL})$,

$\mathrm{V}_{2}=$ Volume of standard $\mathrm{NaOH}$ solution consumed during titration $(\mathrm{mL})$

$\mathrm{M}=$ Weight of chitosan $(\mathrm{g})$.

The number $0.016(\mathrm{~g})$ is the equivalent weight of $\mathrm{NH}_{2}$ group in $1 \mathrm{~mL}$ of standard $1 \mathrm{M} \mathrm{HCl}$ aqueous solution and 0.0994 is the proportion of $\mathrm{NH}_{2}$ group by weight in chitosan.

\section{FTIR analysis of chitosan}

The samples for FTIR analysis were prepared by grinding the dry blended powder of chitin extract with powdered $\mathrm{KBr}$ in the ratio of 1:5 (Sample: $\mathrm{KBr}$ ) and then compressed to form discs ${ }^{[17-}$ 19]. Spectra were measured on films using an attenuated total refraction (ATR) method in a FTIR Spectrophotometer Spectrum - bx model Perkin Elmer [17-19].

\section{Chitosan solution preparation}

$1 \%$ chitosan solution was prepared by adding $1 \mathrm{~g}$ (dry basis) of chitosan to $100 \mathrm{~mL}$ of water, and thereafter mixed with $100 \mathrm{ml}$ of $2 \%$ acetic acid solution until it dissolved completely [20, 21].

\section{Optimum dose determination and rubber processing effluent (RPE) treatment with chitosan}

As earlier reported by Ize-Iyamu et al. [22], the optimum dose for the effective use of chitosan for rubber processing effluent treatment was investigated with equal amounts of the various effluent samples $(100 \mathrm{~mL})$ but with varying amount of the coagulant (chitosan) for each determination and its $\mathrm{pH}$ variations. Chitosan optimum dose was found to be $1.40 \mathrm{~mL}$ giving a $87.24 \%$ COD reduction.

In this research work, the optimum dose of Iron (III) Chloride was also determined likewise via jar testing. The effluent was treated based on their optimum dosages and the physicochemical characteristics of the treated effluent with chitosan and Iron (III) Chloride respectively were determined.

The COD determinations were carried out using similar amount of the effluent sample but while varying the amount of coagulant added at each determination [22].

$$
\% \text { COD reduction }=\frac{\text { COD raw }- \text { COD treated }}{\text { COD raw }} \times 100
$$

COD raw $=$ COD of the raw (untreated) effluent

\section{Characterization techniques}

The untreated and treated rubber processing effluent samples, as well as the chitosan extract, were analyzed according to standard methods $[23,4]$.

Conductivity/TDS meter -DDS-307A was used to determine the turbidity and electrical conductivity levels. $0.01 \mathrm{M}$ and $0.001 \mathrm{M} \mathrm{KCl}$ standards solution were prepared from dry $\mathrm{KCl}$ reagent grade for calibration. Dissolved oxygen level was determined using Alkaline-Azide modification of Winkler's method. Chemical oxygen demand was determined using dichromate reflux method. BOD was determined after 5 days incubation at $20{ }^{\circ} \mathrm{C}$ and after dilution $(2 \%$ dilution water), at the end of which the dissolved oxygen was determined. Sodium and potassium were determined by flame photometric methods, calcium and magnesium were determined by EDTA method. Heavy metals analysis was carried out using an atomic absorption spectrophotometer.

\section{Results and Discussion}

\section{Analysis of chitosan used as coagulants}

Table 1 shows the $\mathrm{pH}$ and elemental analysis of chitosan extracted from prawn heads. From the results, chitosan was observed to be weakly alkaline at a $\mathrm{pH}$ of 8.20 with high Electrical conductivity (EC) value of 1060.00 NTU. This indicates the presence of mobile ions (trivalent, divalent and some monovalent ions). The presence of these types of ions has been shown to enhance the coagulating and flocculating potentials of materials [5]. 
Table 1. Physico-chemical analysis of the obtained chitosan

\begin{tabular}{|l|c|}
\hline \multicolumn{1}{|c|}{ Parameters } & Chitosan \\
\hline $\mathrm{pH}$ & $8.20 \pm 0.25$ \\
\hline E.C $\mu \mathrm{s} / \mathrm{cm}$ & $1060.00 \pm 0.00$ \\
\hline Iron $(\mathrm{mg} / \mathrm{kg})$ & $7.54 \pm 0.22$ \\
\hline Aluminum $(\mathrm{mg} / \mathrm{kg})$ & $3.70 \pm 0.20$ \\
\hline Manganese $(\mathrm{mg} / \mathrm{kg})$ & $22.26 \pm 0.85$ \\
\hline Zinc $(\mathrm{mg} / \mathrm{kg})$ & $19.00 \pm 0.72$ \\
\hline Calcium $(\mathrm{mg} / \mathrm{kg})$ & $10.40 \pm 1.50$ \\
\hline Magnesium $(\mathrm{mg} / \mathrm{kg})$ & $21.70 \pm 1.00$ \\
\hline Sodium $(\mathrm{mg} / \mathrm{kg})$ & $12.05 \pm 0.75$ \\
\hline Potassium $(\mathrm{mg} / \mathrm{kg})$ & $10.90 \pm 0.55$ \\
\hline
\end{tabular}

Fig. 1 presents the Fourier Transform Infrared spectroscopic analysis of the extracted chitosan. The result shows the presence of the free amino functional group in the chitosan matrix after N-deacetylation of chitin whiskers. A change which was attributed to the N-deacetylation of chitin was also observed in the crystallinity and polymorphic nature of chitosan.

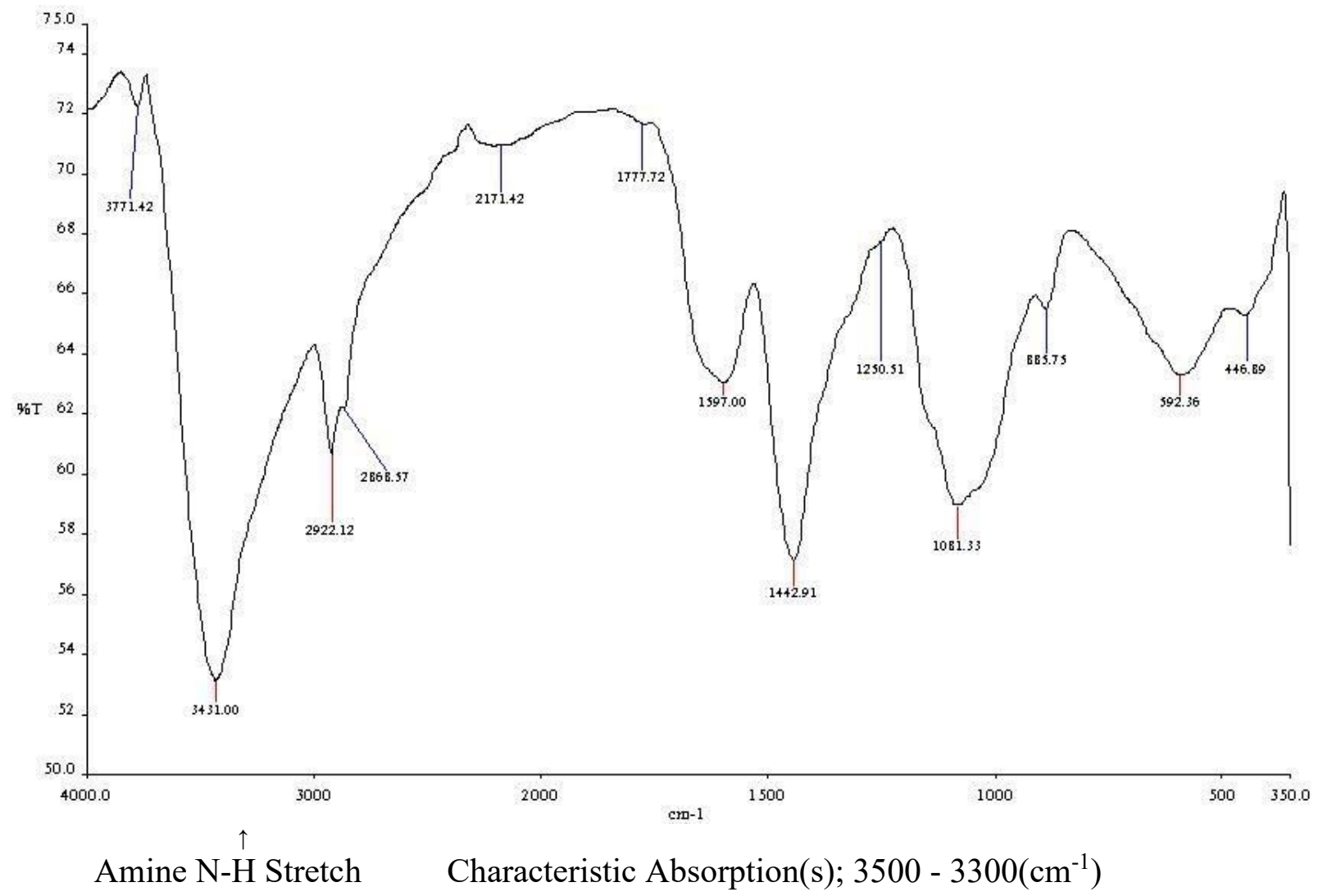

Figure 1. Fourier Transform Infra-Red (FTIR) Analysis of Chitosan

The band at $3431.00 \mathrm{~cm}^{-1}$ displayed a greater intensity than the one at $1442.91 \mathrm{~cm}^{-1}$ and shows the effective deacetylation of chitin. The sharp peak at $3500-3300\left(\mathrm{~cm}^{-1}\right)$ indicates the amine $\mathrm{N}-\mathrm{H}$ Stretch of the chitosan which further confirms removal of the acetyl group $\left(\mathrm{CH}_{3} \mathrm{CO}\right)$ from the chitin matrix with the $\mathrm{N}$-acetylglucosamine unit $\left(\mathrm{NHCH}_{3} \mathrm{C}=\mathrm{O}\right)$ and hence the presence of the $\beta(1 \rightarrow 4)$-linked D-glucosamine (deacetylated) unit. 
Fig. 2 is a graphical presentation of the optimum dose determined using the synthetic coagulant (Iron (III) Chloride). At pH 5.5, the optimum dose was found to be at $2.50 \mathrm{~g}$. It is also important to state here that the synthetic coagulants are known to be $\mathrm{pH}$ dependent [24] and chitosan has also been found to be effective independent of $\mathrm{pH}$ [22].

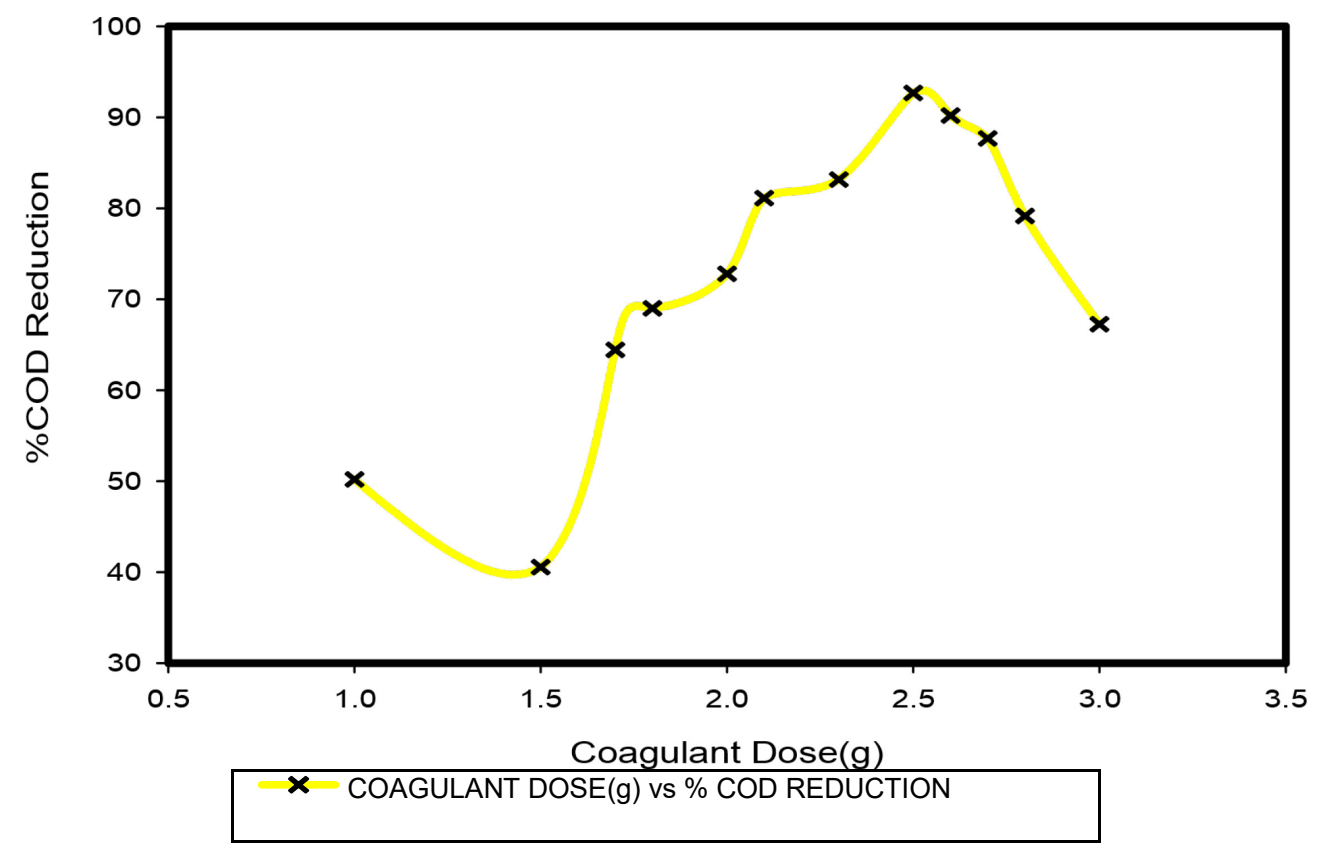

Figure 2. Optimum Dose Determination using Iron (111) Chloride at pH 5.5

\section{Rubber processing effluent treatment with chitosan in comparison with the iron (iii) chloride}

Table 2 present shows the impact of the coagulating properties of chitosan and iron (III) chloride in the treatment of rubber processing effluent via coagulation and flocculation method. The results obtained were compared with World Health Organization (WHO) and Federal Ministry of Environment (FMEnv) regulatory discharge standards respectively.

Chitosan was used at the $\mathrm{pH}$ of the effluent since it has been established to be $\mathrm{pH}$ independent while the $\mathrm{pH}$ of 5.5 was used for Iron (III) Chloride because of its $\mathrm{pH}$-dependent properties.

As seen in Table 2, the effluent samples improved remarkably after treatment with chitosan at an optimum dose of $2.50 \mathrm{~g}$. The measured physico-chemical parameters of the effluent samples used as indicators were comparable for both Iron (III) Chloride and chitosan.

The Dissolved Oxygen (DO) level determines the survival of aquatic life in water bodies. The DO of the untreated effluent was found to be low with a value of $0.63 \pm 0.25 \mathrm{mg} / \mathrm{L}$ when compared with the permissible limits of environmental discharge standards. However, on treating with chitosan and Iron (III) chloride, the DO increased and was found to be $3.90 \pm 0.31$ and $3.90 \pm 1.02 \mathrm{mg} / \mathrm{L}$ respectively. 
Table 2. Results obtained from the physicochemical characterization of the untreated/treated RPE with Chitosan and Iron (III) chloride respectively compared with regulatory discharge standard; FMEnv and WHO standards (Mean \pm SD) from triplicate determinations)

\begin{tabular}{|c|c|c|c|c|c|}
\hline Parameter & Untreated RPE & $\begin{array}{l}\text { Treated RPE } \\
\text { Chitosan }\end{array}$ & $\begin{array}{l}\text { Treated RPE with } \\
\text { Iron(III)Chloride }\end{array}$ & $\begin{array}{l}\text { FMEnv } \\
\text { Standard }\end{array}$ & $\begin{array}{l}\text { WHO } \\
\text { Standard }\end{array}$ \\
\hline $\mathrm{pH}$ & $6.70 \pm 0.20$ & $6.60 \pm 0.10$ & $5.00 \pm 0.09$ & $6.00-8.50$ & $6.00-8.50$ \\
\hline Temperature $\left({ }^{\circ} \mathrm{C}\right)$ & $25.30 \pm 0.03$ & $24.50 \pm 1.02$ & $25.20 \pm 0.01$ & Ambient & Ambient \\
\hline $\mathrm{E} \mathrm{C}(\mu \mathrm{S} / \mathrm{cm})$ & $625.00 \pm 1.42$ & $47.88 \pm 0.11$ & $10.05 \pm 0.00$ & 200.00 & 200.00 \\
\hline Turbidity (NTU) & $38.00 \pm 1.00$ & $1.60 \pm 0.01$ & $6.40 \pm 0.01$ & 10.00 & 10.00 \\
\hline TSS (mg/L) & $178.00 \pm 2.00$ & $241.58 \pm 1.25$ & $264.46 \pm 1.40$ & 100 & 100 \\
\hline $\mathrm{TDS}(\mathrm{mg} / \mathrm{L})$ & $32.00 \pm 1.10$ & $20.22 \pm 0.20$ & $20.74 \pm 0.51$ & 10 & 10 \\
\hline TS (mg/L) & $210.00 \pm 2.05$ & $261.80 \pm 1.15$ & $285.20 \pm 1.40$ & 1000.00 & 1000.00 \\
\hline $\mathrm{DO}(\mathrm{mg} / \mathrm{L})$ & $2.63 \pm 0.25$ & $3.90 \pm 0.31$ & $5.60 \pm 1.02$ & 5.00 & $5.00-6.00$ \\
\hline $\mathrm{BOD}(\mathrm{mg} / \mathrm{L})$ & $312.00 \pm 1.30$ & $42.44 \pm 0.95$ & $14.30 \pm 0.20$ & 30.00 & 30.00 \\
\hline $\mathrm{COD}(\mathrm{mg} / \mathrm{L})$ & $1069.58 \pm 2.42$ & $135.60 \pm 1.07$ & $86.20 \pm 1.07$ & 250.00 & 250.00 \\
\hline $\mathrm{HCO}_{3}^{-}(\mathrm{mg} / \mathrm{L})$ & $85.40 \pm 1.03$ & $12.70 \pm 1.05$ & $9.20 \pm 0.07$ & 30.00 & 30.00 \\
\hline Potassium(mg/L) & $61.30 \pm 0.15$ & $0.82 \pm 0.02$ & $0.12 \pm 0.03$ & - & - \\
\hline Calcium(mg/L) & $5.00 \pm 0.00$ & $1.20 \pm 0.05$ & $1.35 \pm 0.01$ & 25.00 & 25.00 \\
\hline Magnesium(mg/L) & $5.27 \pm 0.21$ & $4.43 \pm 0.12$ & $0.47 \pm 0.02$ & 50.00 & - \\
\hline Chlorides (mg/L) & $56.70 \pm 0.03$ & $7.30 \pm 0.30$ & $1.77 \pm 0.11$ & 250.00 & 350.00 \\
\hline Phosphates (mg/L) & $24.20 \pm 0.10$ & $0.61 \pm 0.05$ & $0.57 \pm 0.10$ & 3.50 & 3.50 \\
\hline $\mathrm{NH}_{4}-\mathrm{N}(\mathrm{mg} / \mathrm{L})$ & $110.75 \pm 0.01$ & $0.01 \pm 0.13$ & $3.35 \pm 0.09$ & 50.00 & 50.00 \\
\hline $\mathrm{NO}_{2}-\mathrm{N}(\mathrm{mg} / \mathrm{L})$ & $20.03 \pm 0.01$ & $0.01 \pm 0.11$ & $1.42 \pm 0.05$ & 20.00 & 20.00 \\
\hline $\mathrm{NO}_{3}-\mathrm{N}(\mathrm{mg} / \mathrm{L})$ & $60.15 \pm 0.02$ & $0.02 \pm 0.02$ & $2.09 \pm 0.01$ & 40.00 & 50.00 \\
\hline $\operatorname{Iron}(\mathrm{mg} / \mathrm{L})$ & $1.98 \pm 0.04$ & $0.21 \pm 0.02$ & $0.40 \pm 0.05$ & 0.30 & 0.50 \\
\hline $\operatorname{Zinc}(\mathrm{mg} / \mathrm{L})$ & $0.14 \pm 0.05$ & $0.06 \pm 0.00$ & $0.06 \pm 0.01$ & 0.20 & 2.40 \\
\hline Chromium(mg/L) & $0.29 \pm 0.03$ & $0.01 \pm 0.02$ & $0.01 \pm 0.00$ & 0.10 & 0.10 \\
\hline Lead(mg/L) & $0.17 \pm 0.01$ & $0.00 \pm 0.00$ & $0.04 \pm 0.00$ & 0.10 & 0.10 \\
\hline
\end{tabular}

$\mathrm{SD}=$ Standard Deviation

A remarkable reduction in Turbidity, Biochemical Oxygen Demand (BOD) and the Chemical Oxygen Demand (COD) levels were also observed for the treated samples. The turbidity decreased from $38.00 \pm 1.00 \mathrm{NTU}$ to $1.60 \pm 0.01$ for Chitosan treated effluent sample and $6.40 \pm 0.01 \mathrm{NTU}$ for iron (iii) chloride treated effluent samples. The COD decreased from $1176.00 \mathrm{mg} / \mathrm{L}$ to $135.60 \pm 1.07$ and $86.20 \pm \mathrm{mg} / \mathrm{L}$, for chitosan and Iron (III) Chloride respectively. The BOD levels also decreased from $312.00 \pm 1.30$ to $42.44 \pm 0.95$ and $14.30 \pm 0.20 \mathrm{mg} / \mathrm{L}$ for chitosan and Iron (III) Chloride respectively.

Table 3 shows the percentage (\%) change of the physico-chemical properties after treatment with chitosan and iron (III) chloride respectively. The results signify a reduction in the level of pollution as reduction decrease in electrical conductivity by over $90 \%$ was observed for the chitosan treated effluent sample. Parameters that are pollution indicators such as COD, BOD and Turbidity reduced significantly. $88.39 \%$ reduction in COD, $83.40 \%$ reduction BOD and $95.79 \%$ reduction in turbidity were observed for chitosan treated effluents. The reduction in the turbidity levels after treating with chitosan was observed to be above $90 \%$. This can be attributed to the fact that most of the colloidal particles have been removed by the natural biopolymer. 
Table 3. Percentage (\%) change (reduction/increase) of each parameter after rpe treatment with chitosan and iron (III) chloride respectively

\begin{tabular}{lll}
\hline Parameters (\% Change) & Chitosan & Iron(III)Chloride \\
\hline E C $\mu$ S/cm & 92.34 & 98.39 \\
Turbidity NTU & 95.79 & 77.89 \\
Suspended Solids (mg/L) & 35.72 & 49.13 \\
Dissolved Solids (mg/L) & 36.81 & 35.18 \\
Total Solid (mg/L) & 24.66 & 35.00 \\
DO (mg/L) & 519.05 & 519.05 \\
BOD (mg/L) & 83.40 & 95.42 \\
COD (mg/L) & 88.39 & 95.30 \\
Bicarbonates(mg/L) & 85.13 & 89.23 \\
Potassium(mg/L) & 98.66 & 99.32 \\
Calcium(mg/L) & 95.20 & 94.60 \\
Magnesium(mg/L) & 15.94 & 91.08 \\
Chlorides(mg/L) & 87.13 & 96.87 \\
Phosphates(mg/L) & 97.47 & 97.64 \\
$\mathrm{NH}_{4}-\mathrm{N}(\mathrm{mg} / \mathrm{L})$ & 99.99 & 96.98 \\
$\mathrm{NO}_{2}-\mathrm{N}(\mathrm{mg} / \mathrm{L})$ & 99.99 & 92.91 \\
$\mathrm{NO}_{3}-\mathrm{N}(\mathrm{mg} / \mathrm{L})$ & 99.16 & 96.52 \\
Iron(mg/L) & 88.88 & 77.27 \\
Zinc(mg/L) & 85.71 & 85.71 \\
Chromium(mg/L) & 96.55 & 97.41 \\
Lead(mg/L) & 98.82 & 78.82 \\
\hline
\end{tabular}

The Total Solid contents (TS); Dissolved solid (DS) and Suspended Solids (SS) increased by over $20 \%$ using chitosan; an indication that colloidal/particulate matters hitherto present in the effluent samples were removed. 35\% Total solid increase was observed using Iron (III) Chloride. The nutrients levels also reduced appreciably, with the ammonia nitrogen $\left(\mathrm{NH}_{4}-\mathrm{N}\right)$, nitrite $\left(\mathrm{NO}_{2}-\mathrm{N}\right)$ and nitrate $\left(\mathrm{NO}_{3}-\mathrm{N}\right)$ levels decreasing by $99 \%$ respectively. This remarkable trend was also observed with other micronutrients such as phosphate and potassium which are responsible for the eutrophication of water bodies when untreated effluent are discharged directly into them, the decreased were found to be above $99.00 \%$ after treatment with the chitosan and Iron (III) Chloride. Appreciable reductions in the heavy metals content were also observed. 


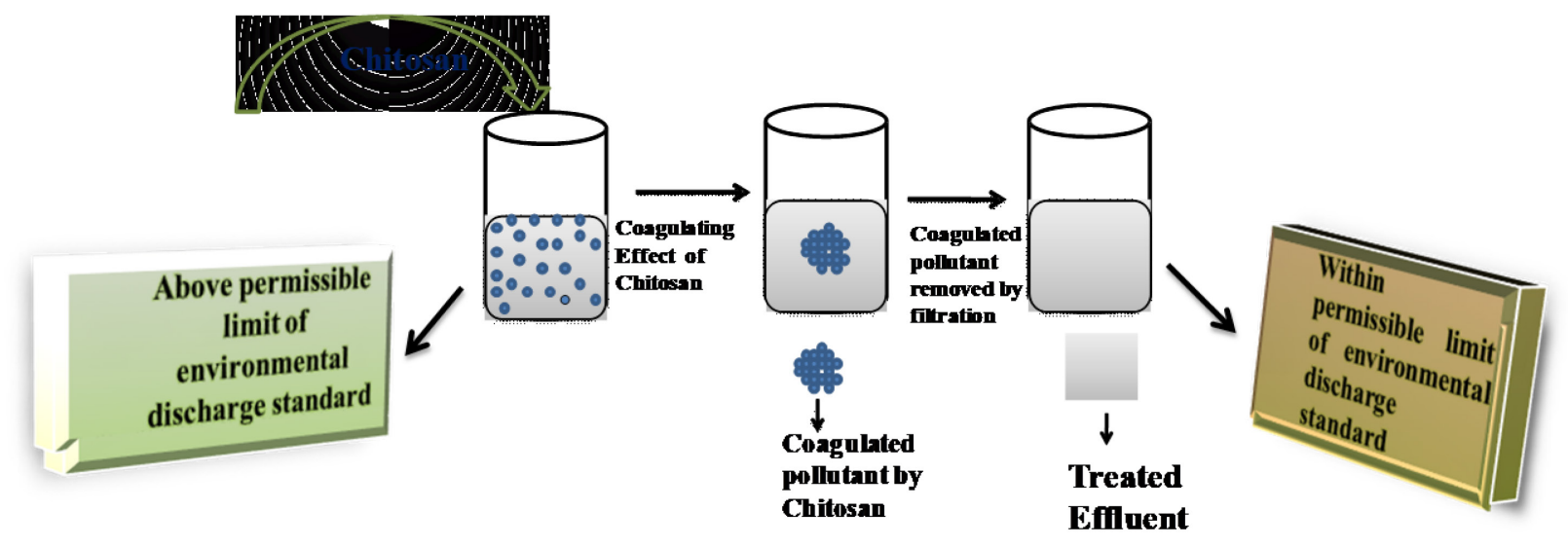

Figure 3. Graphical illustration of coagulation and flocculation treatment method

\section{Conclusion}

The treatment of rubber processing effluent (RPE) with chitosan by coagulation and flocculation method was effective. In comparison to biological methods adopted in recent times to treat rubber processing effluent, Kantachote and Innuwat, (2004) [25] reported the combined aerobic and anaerobic digestion has been used for biogas production from rubber wastewater. This treatment resulted in the formation of $\mathrm{H} 2 \mathrm{~S}$ due to consumption of sulphate instead of oxygen by sulphate-reducing bacteria. $\mathrm{H}_{2} \mathrm{~S}$ is toxic and increases the smell of putrid eggs. The gas also causes a big problem in biogas producing systems [25]. As a result, sulphide could inhibit the activity of methane producing bacteria due to its toxicity. It also revealed that the high amount of sulphide reduced the COD removal.

However, the treatment method used in this study didn't have the aforementioned drawbacks of $\mathrm{H}_{2} \mathrm{~S}$ formation and also has the advantage of being efficient, cheap and environmentally friendly.

The results obtained also compared favourably with the synthetic coagulant used and proven to be effective for safe disposal of RPE meeting the allowable limits of regulatory discharge standards.

\section{Conflict of Interest}

No potential conflict of interest was reported by authors.

\section{Acknowledgement}

The authors appreciate the support of the management of Rubber Research Institute of Nigeria. They are also grateful to the Centre for Energy and Research, University of Benin, Product Development laboratory, Rubber Research Institute of Nigeria and McGill Laboratory, M.M Way, Benin city, Nigeria.

\section{Funding}

Rubber Research Institute of Nigeria 


\section{References}

[1] M.A. Meyers, Biological materials: structure \& mechanical properties, Progress in Materials Science. 53 (2008) 1.

[2] C. Saikia, P. Gogoi, T.K. Maji, Chitosan: a promising biopolymer in drug delivery applications, J. Mol. Genet. Med. S4 (2015) 006.

[3] P. Kanmani et al., Environmental applications of chitosan and cellulosic biopolymers: A comprehensive outlook, Bioresour. Technol. 242 (2017) 295-303.

[4] C.M.A. Ademoroti, Standard methods for water and effluent analysis, Foludex Press Ltd., Ibadan. 3 (1996) 29-118.

[5] W.J. Weber Jr, Physicochemical processes of water quality control, New York: J Wiley \& Sons Inc., 1972, pp. 46-71.

[6] M.R. Jekel, B. Heinzmann, Residual aluminum in drinking-water treatment, JWSRT-Aqua. 38 (1989) 281-288.

[7] C.Y. Yin, Emerging usage of plant - based coagulants for water and wastewater treatment, Process Boichemistry. 45(9) (2010) 1437-1444.

[8] RSCM de Queiroz Antonino et al., Preparation and characterization of chitosan obtained from shells of shrimp (Litopenaeus vannamei Boone), Mar. Drugs. 15(5) (2017) 141.

[9] V.L. Oliveira et al., Preparation and characterization of chitosan obtained from shells of shrimp (Litopenaeus vannamei Boone), Mar. Drugs, 15 (2017) 141.

[10] J. Nitschke et al., A new method for the quantification of chitin and chitosan in edible mushrooms, Carbohydrate Research. 346(11) (2011) 1307-1310.

[11] L.R.R. Berger et al., Agroindustrial waste as alternative medium in the production of chitin and chitosan by Rhizopus arrhizus - a factorial design, Asian Chitin Journal. 7 (2011) 83-90.

[12] V.J. José Carlos et al., Physicochemical and antibacterial properties of chitosan extracted from waste shrimp shells, Journal of Microbiology. (2016) Article ID 5127515.

[13] I. Younes, O. Ghorbel-Bellaaj, M. Chaabouni, Use of a fractional factorial design to study the effects of experimental factors on the chitin deacetylation, International Journal of Biological Macromolecules. 70 (2014) 385-390.

[14] T.C.M. Stamford et al., Microbiological chitosan: potential application as anticariogenic agent, in: Practical Applications in Biomedical Engineering, InTech, Rijeka, Croatia, ${ }^{\text {st }}$ Ed. 9 (2013) 229-244

[15] O.C. Ize-Iyamu et al., Characterization and treatment of sludge from the rubber processing industry with locally sourced coagulants (chitosan and Jatropha gossypifolia stem latex), Proceedings at the International Rubber Conference, Ho Chi Minh City, Vietnam, 2015, pp. 398-404.

[16] N.V. Toan, Production of chitin and chitosan from partially autolized shrimp shell materials, The Open Biomaterials Journal. 1 (2009) 21-24.

[17] M.S. Hossain, A. Iqbal, Production and characterization of chitosan from shrimp waste, J. Bangladesh Agric. Uni. 12(1) (2014) 153-160.

[18] T. Bourtoom, M.S. Chinnan, Preparation and properties of rice starch-chitosan blend biodegradable film, LWT-Food Sci. Technol. 41 (2008) 1633-1641.

[19] J. Yang et al., Growth of apatite on chitosan-multiwall carbon nanotube composite membranes, Appl. Surf. Sci. 255 (2009) 8551-8555. 
[20] W. Sajomsang et al., Mucoadhesive property and biocompatibility of methylated N-aryl chitosan derivatives, Carbohydr. Polym. 78 (2009) 945-952.

[21] K.N. Hong, P.S. Meyers, Crawfish chitosan as a coagulant in recovery of organic compounds from seafood processing streams, Journal of Agricultural Food Chemistry, American Chemical Society. 37 (1989) 580-583.

[22] O.K. Ize-Iyamu et al., Characterization and treatment of sludge from the brewery using chitosan, The Pacific Journal of Science and Technology. 12(1) (2011) 542-547.

[23] O.C. Ize-Iyamu et al., The effects of $\mathrm{pH}$ in the treatment of rubber processing effluent using chitosan, Centrepoint Journal (Science Edition). 21(2) (2015) 94-106.

[24] American Public Health Association APHA (2005): Standard Methods for the Examination of Water and Waste water, $16^{\text {th }}$ Ed., Washington, D.C.

[25] C.M.A. Ademoroti, Environmental Chemistry and Toxicology, Foludex Press Ltd. Ibadan, Nigeria. Ltd., 1996, pp. 111-120.

[26] D. Kantachote, W. Innuwat, Isolation of Thiobacillus sp. for use in treatment of rubber sheet wastewater, Songklanakarin Journal of Science and Technology. 26(5) (2004) 649-657. 